\title{
Synthesis and homopolymerization studies of vinylimidazolium salts
}

\author{
J. C. Salamone*, S. C. Israel, P. Taylor and B. Snidert
}

\author{
Polymer Science Program, Department of Chemistry, Lowell Technological Institute, \\ Lowell, Mass. 01854, USA and \\ Macromolecular Research Center, University of Michigan, Ann Arbor, Michigan 41805, USA \\ (Received 27 April 1973; revised 24 July 1973)
}

\begin{abstract}
The preparations and characterizations of several monomeric vinylimidazolium salts are presented from the quaternizations of 1-vinylimidazole and 2-methyl-1-vinylimidazole with $\mathrm{n}$-alkyl iodides and with dimethyl sulphate. Although vinylimidazolium salts have been reported in the patent literature, many of these salts were not isolated and characterized prior to their polymerization. From the reactions of 1 -vinylimidazole with $n$-alkyl iodides, a homologous series of 3 -n-alkyl-1-vinylimidazolium iodides were prepared in which the longer chain derivatives appeared to form micelles in aqueous solution. Dicationic crosslinking agents were also prepared through similar quaternization reactions. All the cationic vinyl monomers were homopolymerized in aqueous solution by free radical initiation. The solution behaviour of the resulting polyions indicated that the longer side-chain polyions had polysoap properties.
\end{abstract}

\section{INTRODUCTION}

The free radical polymerization of cationic vinyl monomers has been an area of increased interest in recent years ${ }^{1,2}$. Although many such monomers have been synthesized, most of these have contained the positive charge far removed from the double bond. Very few studies have been concerned with monomers in which the positive charge was adjacent to the vinyl group, since these monomers can be difficult to polymerize. However, it has been found that when the cationic site is on an aromatic ring which is adjacent to a double bond, homo- and co-polymerization appears possible. This is illustrated by the free radical polymerizations of various vinylpyridinium ${ }^{3-7}$ salts.

In this work are presented the preparation, characterization and polymerization of a variety of quaternary iodide and methylsulphate salts from 1-vinylimidazole and 2-methyl-1-vinylimidazole. Although mention has been made in the patent literature on the free radical polymerization of vinylimidazolium salts ${ }^{8}$, in many cases these quaternary monomers do not appear to have been isolated and characterized.

\section{EXPERIMENTAL}

\section{Monomer preparations}

3-Methyl-1-vinylimidazolium iodide (Ia). To $9 \cdot 41 \mathrm{~g}$ $(0.10 \mathrm{~mol})$ of freshly distilled 1-vinylimidazole was added $85.20 \mathrm{~g}(0.60 \mathrm{~mol})$ of reagent grade methyl iodide in $100 \mathrm{ml}$ of dry ethyl acetate at $-10^{\circ} \mathrm{C}$. The reaction mixture was stirred for $1 \mathrm{~h}$ and then brought to room

* To whom enquiries should be addressed.

$\dagger$ Present address: Dept. of Chemistry, Harvard University, Cambridge, Mass., USA. temperature overnight, during which time off-white crystals formed. The mixture was cooled and filtered, and the monomeric salt was washed three times with anhydrous diethyl ether, followed by three recrystallizations from n-propanol giving a $56 \%$ yield of off-white needles, m.p. $77 \cdot 5-78 \cdot 0^{\circ} \mathrm{C}$ (lit. $85-86^{\circ} \mathrm{C}$ ) ${ }^{9}$.

Calculated for $\mathrm{C}_{6} \mathrm{H}_{9} \mathrm{~N}_{2} \mathrm{I}: \mathrm{C}, 30.53 \% ; \mathrm{H}, 3.84 \%$; $\mathrm{N}, 11.87 \%$; I, 53.76\%. Found: C, $30.44 \%$; H, 3.79\%; $\mathrm{N}, 11 \cdot 82 \% ; \mathrm{I}, 53 \cdot 77 \%$.

3-n-Propyl-1-vinylimidazolium iodide (Ib). This monomer was prepared by a similar procedure to that for Ia except that stirring was conducted for $1 \mathrm{~h}$ at room temperature using $19.4 \mathrm{~g}(0.12 \mathrm{~mol})$ of $n$-propyl iodide. After stirring, the solution was left overnight and an oily product separated. The oil was removed by decantation and triturated with diethyl ether. After a second trituration, solid formed. The quaternary salt was recrystallized from n-propanol giving a $58.9 \%$ yield with m.p. $68 \cdot 0$ $68 \cdot 5^{\circ} \mathrm{C}$.

Calculated for $\mathrm{C}_{8} \mathrm{H}_{13} \mathrm{~N}_{2} \mathrm{I}: \mathrm{C}, 36.38 \% ; \mathrm{H}, 4.97 \%$; $\mathrm{N}, 10.60 \%$; I, $48.05 \%$. Found: C, $36.32 \%$; H, $5.14 \%$; $\mathrm{N}, 10 \cdot 28 \% ; \mathrm{I}, 48 \cdot 35 \%$.

3-n-Hexyl-1-vinylimidazolium iodide (Ic). To $10 \cdot 60 \mathrm{~g}$ $(0.050 \mathrm{~mol})$ of $\mathrm{n}$-hexyl iodide in $25 \mathrm{ml}$ of dry ethyl acetate at room temperature was added with stirring $2.35 \mathrm{~g}$ $(0.025 \mathrm{~mol})$ of 1-vinylimidazole. Stirring was continued for $8 \mathrm{~h}$, during which time a light yellow oil separated. The product, which remained as an oil after several triturations with diethyl ether, was obtained in $10.5 \%$ yield.

Calculated for $\mathrm{C}_{11} \mathrm{H}_{19} \mathrm{~N}_{2} \mathrm{I}: \mathrm{C}, 43 \cdot 15 \% ; \mathrm{H}, 6.26 \%$; N, 9.15\%; I, $41.45 \%$. Found: C, $42.44 \%$; H, 6.48\%; $\mathrm{N}, 9.44 \% ; \mathrm{I}, 41 \cdot 74 \%$. 
3-n-Heptyl-1-vinylimidazolium iodide (Id). This monomer was prepared by a procedure similar to that for Ic except that the same molar amount of $n$-heptyl iodide was used. The reaction was stirred for $48 \mathrm{~h}$, after which time the oily layer which formed was separated by decantation. After repeated triturations with diethyl ether, the product remained as an oil and was obtained in $17.5 \%$ yield.

Calculated for $\mathrm{C}_{12} \mathrm{H}_{21} \mathrm{~N}_{2} \mathrm{I}: \mathrm{C}, 45.01 \% ; \mathrm{H}, 6.61 \%$; N, $8.75 \%$; I, 39.63\%. Found: C, $44.82 \% ; \mathrm{H}, 6.80 \%$; $\mathrm{N}, 8 \cdot 77 \% ; \mathrm{I}, 39 \cdot 77 \%$.

3-n-Dodecyl-1-vinylimidazolium iodide (Ie). To $3.55 \mathrm{~g}$ $(0.012 \mathrm{~mol})$ of n-dodecyl iodide in $100 \mathrm{ml}$ of dry ethyl acetate was added $1.00 \mathrm{~g}(0.0106 \mathrm{~mol})$ of 1-vinylimidazole. After stirring the mixture for $48 \mathrm{~h}$ at room temperature, the solution was cooled to $0^{\circ} \mathrm{C}$, and crystallization of the quaternary salt rapidly occurred. The crystals were filtered, washed with diethyl ether and recrystallized three times from ethyl acetate giving $2.02 \mathrm{~g}(51.0 \%$ yield) of off-white needles, m.p. $50 \cdot 3-51 \cdot 8^{\circ} \mathrm{C}$.

Calculated for $\mathrm{C}_{17} \mathrm{H}_{31} \mathrm{~N}_{2} \mathrm{I}: \mathrm{C}, 52.30 \% ; \mathrm{H}, 8.01 \%$; N, 7.18\%; I, 32.24\%. Found: C, 52.04\%; H, 8.46\%; $\mathrm{N}, 7 \cdot 08 \% ; \mathrm{I}, 32 \cdot 15 \%$.

3-n-Hexadecyl-1-vinylimidazolium iodide (If). This monomer was prepared by the same procedure as that for Ie except for the utilization of $4.23 \mathrm{~g}(0.012 \mathrm{~mol})$ of $\mathrm{n}$-hexadecyl iodide. After three recrystallizations from ethyl acetate, off-white needles formed in $30 \%$ yield, m.p. $68 \cdot 0-68 \cdot 5^{\circ} \mathrm{C}$.

Calculated for $\mathrm{C}_{21} \mathrm{H}_{39} \mathrm{~N}_{2} \mathrm{I}: \mathrm{C}, 56.50 \% ; \mathrm{H}, 8.81 \%$; N, 6.27\%; I, 28.42\%. Found: C, 56.62\%; H, 9.08\%; $\mathrm{N}, 6 \cdot 14 \% ; \mathrm{I}, 28 \cdot 45 \%$.

2,3-Dimethyl-1-vinylimidazolium iodide (II). Using the same conditions as that for Ia with the exception of conducting the entire reaction at room temperature, it was found that crystals formed rapidly. After washing the off-white crystals with diethyl ether followed by three recrystallizations from n-propanol, a $59.2 \%$ yield was obtained with m.p. $149 \cdot 2-151 \cdot 0^{\circ} \mathrm{C}$.

Calculated for $\mathrm{C}_{7} \mathrm{H}_{11} \mathrm{~N}_{2} \mathrm{I}: \mathrm{C}, 33.62 \% ; \mathrm{H}, 4.43 \%$; N, $11.20 \%$; I, 50.75\%. Found: C, 33.80\%; H, 4.43\%; $\mathrm{N}, 11 \cdot 18 \% ; \mathrm{I}, 50 \cdot 64 \%$.

1,4-Butanediyl-3,3'-bis-1-vinylimidazolium diiodide (IIIa). To a solution of $3 \cdot 10 \mathrm{~g}(0.010 \mathrm{~mol})$ of 1,4 -diiodobutane in $20 \mathrm{ml}$ of dry ethyl acetate was added $1.47 \mathrm{~g}$ $(0.012 \mathrm{~mol})$ of 1-vinylimidazole. After standing at room temperature for two weeks, the mixture was filtered and a crystalline product was obtained. The crystals were washed with ethyl acetate and then diethyl ether, followed by vacuum drying. The dicationic monomer was dissolved in $50 \mathrm{ml}$ of water, $25 \mathrm{ml}$ of acetone were added and the solution was concentrated in vacuo until crystals formed. The solution was stored in a refrigerator until crystallization was complete and the product was then filtered giving a $39 \cdot 2 \%$ yield, m.p. $159 \cdot 0-161 \cdot 0^{\circ} \mathrm{C}$.

Calculated for $\mathrm{C}_{14} \mathrm{H}_{20} \mathrm{~N}_{4} \mathrm{I}_{2}: \mathrm{C}, 33 \cdot 75 \% ; \mathrm{H}, 4.05 \%$; N, $11.25 \%$; I, $50.95 \%$. Found: C, 33.70\%; H, 4.01\%; $\mathrm{N}, 11 \cdot 31 \% ; \mathrm{I}, 50 \cdot 75 \%$.

1,4-Butanediyl-3,3'-bis-2-methyl-1-vinylimidazolium diiodide (IIIb). To a solution of $3 \cdot 10 \mathrm{~g}(0.010 \mathrm{~mol})$ of 1,4-diiodobutane in $100 \mathrm{ml}$ of dry ethyl acetate at room temperature was added $4.33 \mathrm{~g}(0.040 \mathrm{~mol})$ of 2 -methyl-1vinylimidazole. A precipitate began to form within a few minutes. The solution was then stored overnight at $0^{\circ} \mathrm{C}$ and the product was then filtered and washed with ethyl acetate. After recrystallization in acetone-water by the procedure given for IIIa, a 53.3\% yield of 2-methyl-3(4-iodobutyl)-1-vinylimidazolium iodide, m.p. 141.0$144 \cdot 0^{\circ} \mathrm{C}$, was obtained. The uncompletely quaternized product $(1.72 \mathrm{~g}, 0.0042 \mathrm{~mol})$ was dissolved in $20 \mathrm{ml}$ of methanol and heated at $65^{\circ} \mathrm{C}$ for $3 \mathrm{~h}$ with $3.0 \mathrm{~g}(0.028 \mathrm{~mol})$ of 2-methyl-1-vinylimidazole. The solution was cooled and poured into excess ethyl acetate to precipitate the dicationic salt. The final product was filtered, washed with diethyl ether and dried giving a $51 \%$ yield, m.p. $271 \cdot 0-273 \cdot 0^{\circ} \mathrm{C}$.

Calculated for $\mathrm{C}_{16} \mathrm{H}_{24} \mathrm{~N}_{4} \mathrm{I}_{2}: \mathrm{C}, 36.52 \% ; \mathrm{H}, 4.60 \%$; N, $10.65 \%$; I, $48.23 \%$. Found: C, $35.70 \%$; H, $4.54 \%$; $\mathrm{N}, 10.56 \% ; \mathrm{I}, 48 \cdot 18 \%$.

3-Methyl-1-vinylimidazolium methylsulphate (IVa). To $15 \cdot 14 \mathrm{~g}(0 \cdot 12 \mathrm{~mol})$ of freshly distilled dimethyl sulphate in $60 \mathrm{ml}$ of dry ethyl acetate at $-10^{\circ} \mathrm{C}$ was added $9.41 \mathrm{~g}(0.1 \mathrm{~mol})$ of 1-vinylimidazole. A precipitate began to form within $10 \mathrm{~min}$. After standing at $0^{\circ} \mathrm{C}$ for $4 \mathrm{~h}$, the product was filtered, washed with ethyl acetate and then recrystallized from n-butanol. The white crystals were filtered, washed with diethyl ether and dried in vacuo at room temperature giving a $66.5 \%$ yield, m.p. $66 \cdot 6-67 \cdot 9^{\circ} \mathrm{C}$. This product was found to be very hygroscopic.

Calculated for $\mathrm{C}_{7} \mathrm{H}_{12} \mathrm{~N}_{2} \mathrm{SO}_{4}: \mathrm{C}, 38 \cdot 17 \% ; \mathrm{H}, 5.49 \%$; $\mathrm{N}, 12.72 \%$; S, $14.56 \%$. Found: C, $37.63 \%$; H, 5.62\%; $\mathrm{N}, 12.41 \% ; \mathrm{S}, 14.30 \%$.

2,3-Dimethyl-1-vinylimidazolium methylsulphate (IVb). To $18.92 \mathrm{~g}(0.15 \mathrm{~mol})$ of dimethyl sulphate in $60 \mathrm{ml}$ of dry ethyl acetate at $-10^{\circ} \mathrm{C}$ was added $10 \cdot 81 \mathrm{~g}(0 \cdot 10 \mathrm{~mol})$ of freshly distilled 2-methyl-1-vinylimidazole. A precipitate was noted within $5 \mathrm{~min}$. After standing at $0^{\circ} \mathrm{C}$ for $4 \mathrm{~h}$, the monomeric salt was filtered, washed with ethyl acetate and recrystallized from n-propanol. After filtration, white hygroscopic crystals were obtained which were washed with diethyl ether and vacuum dried at room temperature giving a $42.2 \%$ yield with a m.p. of $65 \cdot 0-66 \cdot 2{ }^{\circ} \mathrm{C}$.

Calculated for $\mathrm{C}_{8} \mathrm{H}_{14} \mathrm{~N}_{2} \mathrm{SO}_{4}$ : C, $41.01 \% ; \mathrm{H}, 6.02 \%$; $\mathrm{N}, 11.96 \%$;, $13.69 \%$. Found: C, $40.89 \%$; H, $5.91 \%$; $\mathrm{N}, 11.96 \% ; \mathrm{S}, 13.57 \%$.

\section{Homopolymerization reactions}

All homopolymerization reactions were conducted by the following procedure. To a heavy walled polymerization tube was added $10 \mathrm{ml}$ of a $0.45 \mathrm{M}$ aqueous solution of a monomeric salt (Ia-If, II, IVa, IVb) which contained $1 \mathrm{~mol} \%$ of $4,4^{\prime}$-azobiscyanovaleric acid. The contents of the tube was flushed with nitrogen and sealed in vacuo after utilization of the freeze-thaw technique. The tubes were then placed in a constant temperature bath thermostated at $60^{\circ} \mathrm{C}$ for $20 \mathrm{~h}$. In the cases of the completely water soluble, short chain length polymers ( $\mathrm{Va}, \mathrm{Vb}, \mathrm{VI}$, VIIa, VIIb), the polymeric salt solutions were exhaustively dialysed against de-ionized water and the products were obtained by lyophilization. The intermediate chain length polymers ( $\mathrm{Vc}$ and $\mathrm{Vd}$ ) were completely water insoluble and these products were dissolved in ethanol 
and dialysed against ethanol-water and then water. Polymers Vc and Vd were then obtained in powder form by filtration. In the formation of the long sidechain polymers (Ve and Vf), the solutions turned opaque during the reaction and approximately 30\% water insoluble polymer formed with the remainder existing in an emulsified solution. This solution was dialysed against de-ionized water and then isolated in aqueous solution. The percentage yields and elemental analyses of all polymers are given below.

Poly(3-methyl-1-vinylimidazolium iodide) ( $V a)$ obtained in $60.4 \%$ yield after lyophilization.

Calculated for $\mathrm{C}_{6} \mathrm{H}_{9} \mathrm{~N}_{2} \mathrm{I}: \mathrm{C}, 30.53 \% ; \mathrm{H}, 3.84 \%$; N, $11.87 \%$; I, 53.76\%. Found: C, $30.52 \%$; H, 3.96\%; $\mathrm{N}, 11.65 \% ; \mathrm{I}, 53.69 \%$.

Poly(3-n-propyl-1-vinylimidazolium iodide) ( $\mathrm{Vb}$ ) obtained in $58.9 \%$ yield after lyophilization.

Calculated for $\mathrm{C}_{8} \mathrm{H}_{13} \mathrm{~N}_{2} \mathrm{I}: \mathrm{C}, 36.38 \% ; \mathrm{H}, 4.97 \%$; N, $10.60 \%$. Found: C, 36.30\%; H, $5.09 \% ; \mathrm{N}, 10.50 \%$.

Poly(3-n-hexyl-1-vinylimidazolium iodide) $(V c)$ obtained in $65.0 \%$ yield after filtration.

Calculated for $\mathrm{C}_{11} \mathrm{H}_{19} \mathrm{~N}_{2} \mathrm{I}: \mathrm{C}, 43 \cdot 15 \% ; \mathrm{H}, 6.26 \% ; \mathrm{N}$, $9.15 \% ; \mathrm{I}, 41.45 \%$. Found: C, $43.21 \% ; \mathrm{H}, 6.27 \% ; \mathrm{N}$, $9.54 \% ; \mathrm{I}, 40.74 \%$

Poly(3-n-heptyl-1-vinylimidazolium iodide) (Vd) obtained in $59.8 \%$ yield after filtration.

Calculated for $\mathrm{C}_{12} \mathrm{H}_{21} \mathrm{~N}_{2} \mathrm{I}: \mathrm{C}, 45.01 \% ; \mathrm{H}, 6.61 \%$; N, $8.75 \%$; I, 39.63\%. Found: C, $45.29 \%$; H, 6.66\%; $\mathrm{N}, 9.60 \% ; \mathrm{I}, 38.29 \%$.

Poly(3-n-dodecyl-1-vinylimidazolium iodide) (Ve) obtained in a total yield of $63.1 \%$ (including water-soluble and water-insoluble polymer).

Calculated for $\mathrm{C}_{17} \mathrm{H}_{31} \mathrm{~N}_{2} \mathrm{I}: \mathrm{C}, 52.30 \% ; \mathrm{H}, 8.01 \%$; $\mathrm{N}, 7 \cdot 18 \%$; I, 32.24\%. Found: C, $52.04 \%$; H, 8.46\%; $\mathrm{N}, 7.08 \% ; \mathrm{I}, 32.51 \%$

Poly(3-n-hexadecyl-1-vinylimidazolium iodide) (Vf) obtained in a total yield of $64.7 \%$ (including water-soluble and water-insoluble polymer).

Calculated for $\mathrm{C}_{21} \mathrm{H}_{39} \mathrm{~N}_{2} \mathrm{I}: \mathrm{C}, 56.50 \% ; \mathrm{H}, 8.81 \%$; $\mathrm{N}, 6.27 \%$; I, $28.42 \%$. Found: C, $56.32 \%$; H, $8.62 \%$; $\mathrm{N}, 6.37 \% ; \mathrm{I}, 28.58 \%$.

Poly(2,3-dimethyl-1-vinylimidazolium iodide) (VI) obtained in $53.2 \%$ yield after lyophilization.

Calculated for $\mathrm{C}_{7} \mathrm{H}_{11} \mathrm{~N}_{2} \mathrm{I}: \mathrm{C}, 33.62 \% ; \mathrm{H}, 4.43 \%$; $\mathrm{N}, 11.20 \%$; I, 50.75\%. Found: C, 33.42\%; H, 4.62\%; $\mathrm{N}, 11 \cdot 01 \% ; \mathrm{I}, 50 \cdot 70 \%$.

Poly(3-methyl-1-vinylimidazolium methylsulphate) (VIIa) obtained in $43.9 \%$ yield after lyophilization.

Calculated for $\mathrm{C}_{7} \mathrm{H}_{12} \mathrm{~N}_{2} \mathrm{SO}_{4}$ : C, $38.17 \% ; \mathrm{H}, 5.49 \%$; $\mathrm{N}, 12.72 \% ; \mathrm{S}, 14.6 \%$. Found: C, $38.12 \% ; \mathrm{H}, 5.41 \%$; $\mathrm{N}, 12.67 \% ; \mathrm{S}, 14.54 \%$.

Poly(2,3-dimethyl-1-vinylimidazolium methylsulphate) $(V I I b)$ obtained in $67.6 \%$ yield after lyophilization.

Calculated for $\mathrm{C}_{8} \mathrm{H}_{14} \mathrm{~N}_{2} \mathrm{SO}_{4}$ : C, $41.01 \% ; \mathrm{H}, 6.02 \%$; $\mathrm{N}, 11.96 \%$. Found: C, $41.15 \% ; \mathrm{H}, 6.07 \% ; \mathrm{N}, 12.08 \%$.

\section{Crosslinking reactions}

Copolymerization reactions of 1,4-butanediyl-3,3'-bis1-vinylimidazolium diiodide (IIIa) with 3-methyl-1vinylimidazolium iodide (Ia) and of 1,4-butanediyl-3,3'bis-2-methyl-1-vinylimidazolium diiodide (IIIb) with 2,3-dimethylimidazolium iodide (II) were conducted in a similar manner to that of the homopolymerization reactions. Each solution contained a total monomer concentration of $0.45 \mathrm{M}$ in $10 \mathrm{ml}$ of water of which the crosslinking agent (IIIa or IIIb) amounted to $5 \mathrm{~mol} \%$ of the monocationic salt (Ia or II). After copolymerization at $60^{\circ} \mathrm{C}$ for $24 \mathrm{~h}$ with $1 \mathrm{~mol} \% 4,4^{\prime}$-azobiscyanovaleric acid, the products were obtained as soft gels which were exhaustively dialysed against water followed by lyophilization. The dried sample was then twice slurried in water and centrifuged to separate the soluble and insoluble portions. The reaction between Ia and IIIa gave a $68.5 \%$ yield of which $31.3 \%$ was water insoluble whereas the reaction between II and IIIb gave an $80.5 \%$ yield of which $53.5 \%$ was water insoluble.

\section{RESULTS AND DISCUSSION}

\section{Monomer preparations}

In this work, it was of interest to prepare a homologous series of quaternary vinylimidazolium salts in which the linear alkyl moiety could be increased in chain length. Such a series of monomeric salts could have varied hydrophilic-hydrophobic character such that they could function as 'normal' organic salts with the short alkyl moieties or as detergents with the long alkyl moieties. In a similar fashion, the progression in alkyl chain length would also be expected to effect markedly the solution behaviour of the resulting polycations.

The preparation of a homologous series of vinylimidazolium salts was readily achieved by the quaternization of 1-vinylimidazole (reaction $1, \mathrm{R}=\mathrm{H}$ ) with a series of $\mathrm{n}$-alkyl iodides in ethyl acetate as solvent according to the procedures given in the experimental section. This reaction results in quaternization of the 3-position of 1-vinylimidazole to give the corresponding 3-n-alkyl-1vinylimidazolium iodide (Ia-If).
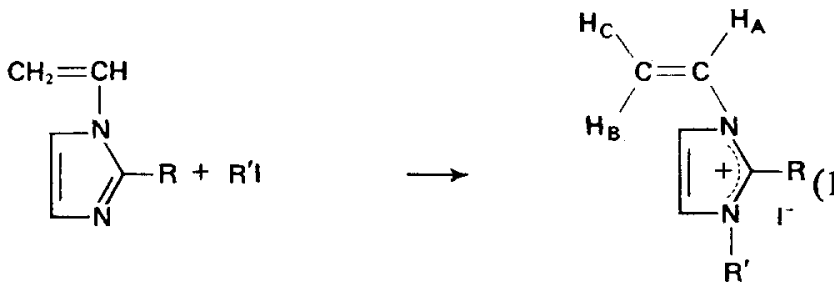

$$
\begin{aligned}
& \text { la: } R=H, R^{\prime}=C_{3} \\
& \text { Ib: } R=H, R^{\prime}=\left(\mathrm{CH}_{2}\right)_{2} \mathrm{CH}_{3} \\
& \text { Ic: } R=H, R^{\prime}=\left(\mathrm{CH}_{2}\right)_{5} \mathrm{CH}_{3} \\
& \text { Id: } R=H, R^{\prime}=\left(\mathrm{CH}_{2}\right)_{6} \mathrm{CH}_{3} \\
& \text { le: } R=H, R^{\prime}=\left(\mathrm{CH}_{2}\right)_{11} \mathrm{CH}_{3} \\
& \text { If: } R=H, R^{\prime}=\left(\mathrm{CH}_{2}\right)_{15} \mathrm{CH}_{3} \\
& \text { II: } R=R^{\prime}=\mathrm{CH}_{3}
\end{aligned}
$$

From the reactions of 1-vinylimidazole with methyl iodide, n-propyl iodide, n-dodecyl iodide and n-hexadecyl iodide, the cationic monomers of 3-methyl(Ia)-, 3-n-propyl(Ib)-, 3-n-dodecyl(Ie)- and 3-n-hexadecyl(If)1 -vinylimidazolium iodide were all obtained in the crystalline form as off-white needles. Upon standing, 
these needles had a tendency to yellow. Although it was possible to obtain crystals of the shortest and longest chain quaternary salts, this was not possible for the intermediate length salts 3-n-hexyl(Ic)- and 3-n-heptyl(Id)1-vinylimidazolium iodide which remained as oils. In spite of the fact that the elemental analysis of the former compound was slightly in error, a verification of the purity of reagents used in the formation of both Ic and Id by gas chromatography indicated that impurities were not the cause of their non-crystallization behaviour. This characteristic is not unexpected, since intermediate chain length hydrocarbons can cause a phase change from a liquid to an oil or solid. For the shortest alkylsubstituted salt (Ia) it was found that this salt is very hygroscopic and difficult to handle. Furthermore, in the formation of this salt, it is possible to form an oil which can be difficult to crystallize. Recently, Shostakovskii et al. ${ }^{9}$ prepared this salt and other vinylimidazolium and vinylbenzimidazolium salts for infra-red and ultra-violet spectral studies. Although these authors reported a melting point of $85-86^{\circ} \mathrm{C}$ in comparison to that which we obtained of $77 \cdot 5-78 \cdot 0^{\circ} \mathrm{C}$, a detailed description of their preparation was not given.

The solubilities of the cationic monomers Ia-If in water were rather interesting. For the short chain length alkyl-substituted salts (Ia and $\mathrm{Ib}$ ), it was found that they were readily soluble in water. For the intermediate chain length alkylated monomers (Ic and Id), these appared to be less water soluble than compounds Ia and $\mathrm{Ib}$, in accord with their greater hydrophobic character. For the long chain length alkyl substituents (Ie and If), it was found that these monomers behaved as detergents in aqueous solution with considerable frothing being noted. The monomer If appeared to be slightly less soluble than Ie. The solubility of the series of monomers in water thus illustrates a distinct change in solution behaviour depending on the length of the quaternary side-chain. The short chain monomers behave as typical water-soluble salts whereas the intermediate chain monomers are less water soluble because of their increased hydrophobic character, and the long chain monomers appear to form micelles in aqueous solution because of their highly hydrophobic character. Transitions in solution behaviour of this type often occur with ionic organic molecules where a hydrophobic moiety can be increased in chain length ${ }^{10}$.

For the monomer 2-methyl-1-vinylimidazole, the only quaternization reaction with an alkyl iodide that was studied was that with methyl iodide (reaction $1, \mathrm{R}=\mathrm{R}^{\prime}=$ $\mathrm{CH}_{3}$ ). It was found that 2,3-dimethyl-1-vinylimidazolium iodide (II) formed very rapidly in comparison to the slower quaternization of 1-vinylimidazole with methyl iodide (reaction 1, Ia). On the basis of stereochemical considerations, this was surprising to note because the more hindered 2-methyl isomer would be expected to quaternize at a slower rate than the less hindered, unsubstituted isomer.

In conjunction with the quaternization of 1-vinylimidazole and 2-methyl-1-vinylimidazole by alkyl iodides, it was also of interest to prepare dicationic monomers that could be used as crosslinking agents. This was effected by the reaction of the nucleophilic vinyl monomers with the alkyl diiodide, 1,4-diiodobutane, in ethyl acetate (reaction 2). In this case it was found that the reaction with 1 -vinylimidazole easily gave the dimeric product 1,4-butanediyl-3,3'-bis-1-vinylimidazolium diio- dide (IIIa). However, the reaction with 2-methyl-1vinylimidazole initially gave the monoquaternized product 2-methyl-3-(4-iodobutyl)-1-vinylimidazolium iodide which underwent complete quaternization upon heating with excess 2-methyl-1-vinylimidazole to 1,4-butanediyl3,3'-bis-2-methyl-1-vinylimidazolium diiodide (IIIb).

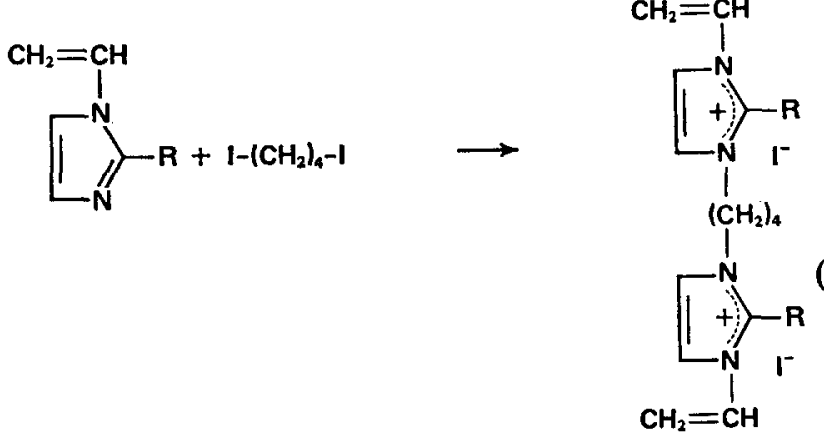

IIla: $\mathbf{R}=\mathrm{H}$

IIIb: $\mathbf{R}=\mathrm{CH}_{3}$
Previously, the only dicationic vinyl monomers that appear to have been reported and characterized have been those prepared from the diquaternization of amino acrylates and methacrylates ${ }^{2}$.

In further studies of the quaternization of 1-vinylimidazole and 2-methyl-1-vinylimidazole, it was also of interest to characterize the salts prepared from the reactions with dimethyl sulphate, since these monomers have been reported in the patent literature but apparently have not been isolated and structurally verified ${ }^{2,9}$. Employing similar quaternization procedures as with the alkyl iodides, it was found that the quaternizations with dimethyl sulphate (reaction 3) occurred within minutes in cold ethyl acetate solution. As was expected, these quaternization reactions were considerably more rapid than the corresponding preparation of the iodide salts. Furthermore, it was again noted that 2-methyl-1vinylimidazole appeared to quaternize more rapidly than its unsubstituted isomer.

$$
\begin{aligned}
& \mathrm{CH}_{2}=\mathrm{CH} \\
& \text { IVa: } \mathrm{R}=\mathrm{H} \\
& \text { IVb: } \mathrm{R}=\mathrm{CH}_{3}
\end{aligned}
$$

The monomers 3-methyl(IVa)- and 2,3-dimethyl(IVb)-1vinylimidazolium methylsulphate were found to be extremely hygroscopic, and utilization of anhydrous conditions was needed in their characterization.

\section{Polymerization reactions}

It was previously indicated that several polyvinylimidazolium salts have been reported in the patent literature in which a variety of vinylimidazoles were quaternized and then free radically homo- or co-polymerized. Alternative preparations of polyvinylimidazolium salts have 
also employed the initial formation of a neutral (nucleophilic) polyvinylimidazole, followed by treatment with an alkylating agent ${ }^{2}$. In the latter approach, it can be difficult to achieve complete quaternization.

In our experiments, we have found that the monomeric salts I, II and IV could be homopolymerized in water using the free radical initiator 4,4'-azobiscyanovaleric acid (ACVA, reaction 4) to their corresponding polyvinylimidazolium salts V-VII.

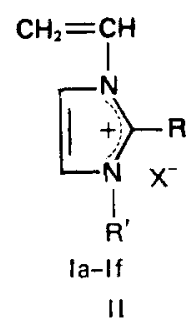

IVa, IVb

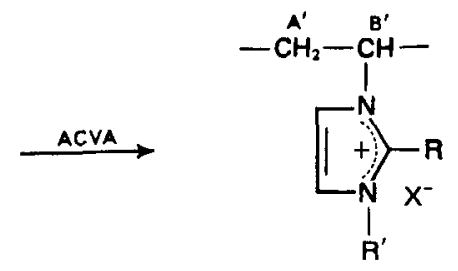

$V: R=H, X^{-}=1^{-}$

Va: $\mathbf{R}^{\prime}=\mathrm{CH}_{3}$

$\mathrm{Vb}: \mathrm{R}^{\prime}=\left(\mathrm{CH}_{2}\right)_{2} \mathrm{CH}_{3}$

Vc: $\mathrm{R}^{\prime}=\left(\mathrm{CH}_{2}\right)_{5} \mathrm{CH}_{3}$

Vd: $R^{\prime}=\left(\mathrm{CH}_{2}\right)_{6} \mathrm{CH}_{3}$

Ve: $R^{\prime}=\left(\mathrm{CH}_{2}\right)_{11} \mathrm{CH}_{3}$

$V f: R^{\prime}=\left(\mathrm{CH}_{2}\right)_{15} \mathrm{CH}_{3}$

VI: $R=R^{\prime}=\mathrm{CH}_{3}, \mathrm{X}^{-}=\mathrm{I}^{-}$

VII: $R^{\prime}=\mathrm{CH}_{3}, X^{-}=\mathrm{CH}_{3} \mathrm{SO}_{4}^{-}$

Vila: $\mathrm{R}=\mathrm{H}$

VIIb: $\mathrm{R}=\mathrm{CH}_{3}$
Each of the homopolymerization reactions were done under the same conditions. The solubilities of the resulting polymeric solutions were found to be related to the length of the alkyl chain. For the homologous alkyl iodide series $\mathrm{Va}-\mathrm{Vf}$, the short side-chain polyions of poly(3-methyl-1-vinylimidazolium iodide)(Va) and poly(3n-propyl-1-vinylimidazolium iodide) ( $\mathrm{Vb}$ ) were found to be very soluble in water. The intermediate side-chain polyions of poly(3-n-hexyl-1-vinylimidazolium iodide) (Vc) and poly(3-n-heptyl-1-vinylimidazolium iodide) (Vd) were completely insoluble in water. On the other hand, the long side-chain polyions poly(3-n-dodecyl-1-vinylimidazolium iodide) (Ve) and poly(3-n-hexadecyl-1-vinylimidazolium iodide) (Vf) gave opaque solutions which frothed easily. From these solutions, it was indicated that the short side-chain polymers $\mathrm{Va}$ and $\mathrm{Vb}$ behaved as normal polyions whereas the long side-chain polyions $\mathrm{Ve}$ and Vf were sufficiently hydrophobic to cause micellarization of the macromolecules in aqueous solution such that polysoaps resulted. The intermediate side-chain length polyions $\mathrm{Vc}$ and $\mathrm{Vd}$ were apparently not sufficiently hydrophobic to cause the formation of polymeric micelles through the hydrophobic intramolecular or intermolecular interactions of the pendant groups. Transitions in solubility behaviour of this type have been reported by Strauss et al. on their studies of poly(4-vinylpyridine) which was first quaternized to a small degree with $\mathrm{n}$-dodecyl bromide followed by greater quaternization with ethyl bromide ${ }^{11,12}$.

In these polymerization reactions, it was noted that when the polysoap solutions were exhaustively dialysed and then lyophilized, the resulting dried solid was insoluble in water, even upon heating. Solubilization could then be effected only through the utilization of organic solutes. It is conceivable that this insolubility could be caused by extensive intermolecular hydrophobic interactions between the long chain pendant groups such that the ionic charges would be buried in the interior and not near the surface as would occur in micellar solutions. A similar water insolubility of a dried anionic polysoap has been previously reported by Sinha and Medalia ${ }^{13}$.

The other short side-chain polyions, poly(2,3-dimethyl1-vinylimidazolium iodide) (VI), poly(3-methyl-1-vinylimidazolium methylsulphate) (VIIa) and poly(2,3-dimethyl-1-vinylimidazolium methylsulphate) (VIIb) were also found to be very water soluble. Since the short sidechain monomers and their corresponding homopolymers were all highly water soluble, it was decided to test the crosslinking ability of the difunctional monomers IIIa and IIIb with the simplest monomeric salts, Ia and II, respectively. Using a $5 \mathrm{~mol} \%$ solution of either crosslinking agent with Ia or II according to the conditions described for the homopolymerizations, followed by several washings with hot water to remove any uncrosslinked polymer, it was found that crosslinked hydrophilic gels resulted. A considerable amount of mechanical loss of crosslinked polymer was obtained by the rigorous purification technique because of the small size of the gel particles that were obtained.

\section{N.m.r. measurements}

N.m.r. spectra of imidazolium salts have been previously reported in the literature ${ }^{14-17}$. Although our preliminary investigation of the n.m.r. spectra of vinylimidazolium salts Ia and II was conducted in $\mathrm{D}_{2} \mathrm{O}^{1}$, as were most of the salts that have been reported in the literature, it was found that this solvent could not be used effectively for the various monomers and polymers because of their wide range in solubility behaviour. It was found, however, the DMSO- $\mathrm{d}_{6}$ could be used for the greatest number of compounds, with only the 2,3dimethyl-substituted iodide polymer (VI) being insoluble at ambient temperature.

The spectral data for the monomeric and polymeric salts prepared in this investigation are given in Tables 1 and 2 , respectively. In both Tables, the substituent positions on the imidazolium ring are given by numbers $1-5$ according to the numbering system shown in reaction (1). In the case of the monomeric salts, the vinyl hydrogens on the 1-position are denoted by A, B and C for positions gem, cis and trans to the imidazolium ring. In the case of the polyions, the chain-backbones are denoted by $\mathrm{A}^{\prime}$ and $\mathrm{B}^{\prime}$ (reaction 4 ) for the methylene and methine hydrogens of the 1-position.

In Table 1, it is seen that there is good agreement in chemical shift values for positions $1-5$ of the monomers of the homologous series (Va-Vf). For each salt, the hydrogen of the 2-position is furthest downfield. In comparison to neutral (unquaternized) imidazole, the 2-hydrogen of each monomeric salt is shifted furthest downfield, apparently because of the cationic character of the 1- and 3-nitrogens. The chemical shifts and coupling constants for the vinyl hydrogens are in accord with those of other cationic, monomeric salts ${ }^{18,19}$. Similar agreement in chemical shift data is also noted for the 2,3-dimethyl-substituted iodide (II), the dicationic crosslinking agents (IIa, IIb) and the methylsulphate salts (IVa, IVb). Relative to our previous spectral study of monomeric salts Ia and II in $\mathrm{D}_{2} \mathrm{O}^{1}$, it is found that ${ }^{D M S O}-\mathrm{d}_{6}$ causes a significant shift downfield for all peak positions. 
Table 1 N.m.r. spectra data of monomeric imidazolium salts in DMSO-d 6

\begin{tabular}{|c|c|c|c|c|c|c|c|c|c|c|c|c|c|c|}
\hline \multirow{3}{*}{$\begin{array}{c}\text { Mono- } \\
\text { mer }\end{array}$} & \multicolumn{10}{|c|}{ Chemical shift, $\delta(\mathrm{ppm})$ from TMS } & & & & \\
\hline & \multicolumn{2}{|c|}{$2 a$} & \multirow[b]{2}{*}{$4,5 b$} & \multicolumn{3}{|c|}{ Vinylc } & \multicolumn{3}{|c|}{ Alkyl } & \multirow{2}{*}{$\begin{array}{l}\text { Counter- } \\
\text { ion }\end{array}$} & \multicolumn{4}{|c|}{ Coupling $(\mathrm{Hz})$} \\
\hline & $\mathbf{H}$ & $\mathrm{CH}_{3}$ & & A & B & C & $\mathrm{N}-\mathrm{CH}_{2}-$ & $-\mathrm{CH}_{2}-$ & $-\mathrm{CH}_{3}$ & & $J_{45}$ & $J_{A B}$ & JAC & $J_{B C}$ \\
\hline la & 9.92 & - & $8 \cdot 34,8 \cdot 14$ & $7 \cdot 48$ & $6 \cdot 11$ & $5 \cdot 53$ & - & - & $3 \cdot 82 \mathrm{~s}$ & - & 1 & 16 & 9 & 2 \\
\hline Ib & $9 \cdot 93$ & - & $8 \cdot 46,8 \cdot 20$ & $7 \cdot 49$ & $6 \cdot 16$ & $5 \cdot 55$ & $4 \cdot 40 t$ & $2 \cdot 35-0 \cdot 95 \mathrm{~m}$ & $0.90 \mathrm{t}$ & 一 & 1 & 16 & 9 & 1.5 \\
\hline Ic & 9.95 & - & $8 \cdot 34,8 \cdot 17$ & $7 \cdot 44$ & 6.09 & $5 \cdot 50$ & $4 \cdot 36 t$ & $2 \cdot 20-1 \cdot 15 \mathrm{~m}$ & $0.89 t$ & - & 1 & 16 & 9 & 2 \\
\hline Id & $9 \cdot 96$ & - & $8 \cdot 40,8 \cdot 14$ & $7 \cdot 51$ & $6 \cdot 15$ & $5 \cdot 52$ & $4 \cdot 44 \mathrm{t}$ & $2 \cdot 30-1 \cdot 05 m$ & $0.86 \mathrm{t}$ & - & 1 & 16 & 9 & $2 \cdot 5$ \\
\hline le & $9 \cdot 90$ & - & $8 \cdot 39,8 \cdot 15$ & $7 \cdot 46$ & $6 \cdot 10$ & $5 \cdot 48$ & $4 \cdot 37 t$ & $2 \cdot 30-1 \cdot 05 m$ & $9 \cdot 89 t$ & - & 1 & 16 & 9 & 2 \\
\hline If & $9 \cdot 80$ & - & $8 \cdot 36,8 \cdot 10$ & $7 \cdot 42$ & $6 \cdot 05$ & $5 \cdot 47$ & $4 \cdot 32 t$ & $2 \cdot 25-1 \cdot 05 m$ & $0.86 t$ & - & 1 & 16 & 9 & 2 \\
\hline II & - & $2 \cdot 81$ & $8 \cdot 20,7 \cdot 89$ & $7 \cdot 58$ & $5 \cdot 96$ & $5 \cdot 45$ & - & - & $3 \cdot 92 \mathrm{~s}$ & - & 2 & 16 & 9 & $2 \cdot 5$ \\
\hline IIIa & $9 \cdot 82$ & - & $8 \cdot 37,8 \cdot 13$ & $7 \cdot 44$ & $6 \cdot 02$ & $5 \cdot 49$ & $4 \cdot 36 t$ & $1 \cdot 91 \mathrm{t}$ & - & - & 1 & 16 & 9 & 2 \\
\hline III b & - & $2 \cdot 89$ & $8 \cdot 29,8 \cdot 04$ & $7 \cdot 47$ & 6.06 & $5 \cdot 53$ & $4 \cdot 40 t$ & $1 \cdot 91 \mathrm{t}$ & - & - & 1 & 16 & 9 & 2 \\
\hline IVa & $9 \cdot 38$ & - & $8 \cdot 13,7 \cdot 88$ & $7 \cdot 26$ & $5 \cdot 93$ & $5 \cdot 45$ & - & - & $3 \cdot 92 \mathrm{~s}$ & $3 \cdot 45 \mathrm{~s}$ & 2 & 16 & 9 & $2 \cdot 5$ \\
\hline IVb & - & $2 \cdot 71$ & $8 \cdot 08,7 \cdot 73$ & $7 \cdot 29$ & $5 \cdot 86$ & $5 \cdot 37$ & - & - & $3 \cdot 86 \mathrm{~s}$ & $3 \cdot 44 \mathrm{~s}$ & 2 & 16 & 9 & $2 \cdot 5$ \\
\hline
\end{tabular}

a All peaks in singlets

b All peaks in doublets

c All peaks in doublets of doublets

Table 2 N.m.r. spectral data of polymeric imidazolium salts in DMSO-d 6

\begin{tabular}{|c|c|c|c|c|c|c|c|c|c|}
\hline \multirow[b]{3}{*}{ Polymer } & \multicolumn{9}{|c|}{ Chemical shifta, $\delta(\mathrm{ppm})$ from TMS } \\
\hline & \multicolumn{2}{|c|}{2} & \multirow[b]{2}{*}{4,5} & \multicolumn{2}{|c|}{ Backbone } & \multicolumn{3}{|c|}{ Alkyl } & \multirow[b]{2}{*}{ Counter-ion } \\
\hline & H & $\mathrm{CH}_{3}$ & & $\mathbf{A}^{\prime}$ & $\mathbf{B}^{\prime}$ & $\mathrm{N}-\mathrm{CH}_{2-}$ & $-\mathrm{CH}_{2}-$ & $-\mathrm{CH}_{3}$ & \\
\hline Va & $9 \cdot 64$ & - & $7 \cdot 70$ & $4 \cdot 20$ & $1 \cdot 70$ & - & - & $3 \cdot 85$ & - \\
\hline Vb & $9 \cdot 62$ & - & $7 \cdot 70$ & $4 \cdot 10$ & $1 \cdot 89$ & $4 \cdot 10$ & $1 \cdot 89$ & 0.92 & - \\
\hline Vc & $9 \cdot 61$ & - & $7 \cdot 83$ & $4 \cdot 23$ & $1 \cdot 34$ & $4 \cdot 23$ & $1 \cdot 34$ & 0.89 & - \\
\hline$V d$ & $9 \cdot 64$ & - & $7 \cdot 71$ & $4 \cdot 20$ & $1 \cdot 27$ & $4 \cdot 20$ & $1 \cdot 27$ & 0.88 & - \\
\hline $\mathrm{Ve}$ & $9 \cdot 60$ & - & $7 \cdot 70$ & $4 \cdot 20$ & $1 \cdot 28$ & $4 \cdot 20$ & $1 \cdot 28$ & 0.92 & - \\
\hline$V f$ & $9 \cdot 70$ & - & $7 \cdot 95$ & $4 \cdot 23$ & $1 \cdot 29$ & $4 \cdot 20$ & $1 \cdot 29$ & 0.86 & - \\
\hline VIla & $9 \cdot 06$ & - & $7 \cdot 70$ & 3.02 & $1 \cdot 77$ & - & - & $3 \cdot 45$ & $3 \cdot 45$ \\
\hline VIIb & - & $2 \cdot 30$ & $7 \cdot 70$ & $3 \cdot 65$ & $1 \cdot 74$ & - & - & $3 \cdot 65$ & 3.65 \\
\hline
\end{tabular}

a All peaks are very broad

For the n.m.r. spectra of the polyions (Table 2), it was again found that good agreement occurred with all chemical shift data. Although the peak positions were rather broad, it can be seen that relative to the monomers in DMSO- $d_{6}$, there are significant upfield shifts for positions 2,4 and 5 . This shift is most likely related to the conversion of the double bond of the monomer to the single bond of the chain-backbone. From these data, it is also apparent that the free radical polymerization of the cationic monomers proceeds through a normal vinyl addition in that there is no alteration of the imidazolium ring. In addition, in none of the spectra of the polymers was any monomer indicated. This is particularly important in the solubility properties of the polysoaps, since it indicates that their solubility in aqueous solution is most likely caused by the micellarization of the polymer chains and not by surrounding monomeric detergent molecules.

\section{CONCLUSION}

This study has illustrated the preparations of a variety of homopolymers of vinylimidazolium salts. In the near future we hope to report further studies on the micellar character of the monomers and polymers as well as on the copolymerization behaviour of the monomeric salts.

\section{ACKNOWLEDGEMENT}

The authors are grateful to Professor C. G. Overberger for his support and encouragement during the early stages of this work.

\section{R EFERENCES}

1 Salamone, J. C., Snider, B., Israel, S. C., Taylor, P. and Raia, D. Polymer Prepr. 1972, 13, 271

2 For a review, see Hoover, M. F. J. Macromol. Sci. (A) 1970, 4, 1327.

3 Duling, I. R. and Price, C. C. J. Am. Chem. Soc. 1962, 84, 578

4 Shyluk, W. P. J. Polym. Sci. (A) 1964, 2, 2191

5 Monagle, D. J. and Mosher, W. A. Polymer Prepr. 1969, 10, 705

6 Georgieva, V. R., Zubov, V. P., Kabanov, V. A. and Kargin, V. A. Dokl. Acad. Nauk SSSR 1970, 190, 1128

7 Gavurina, R. K., Karkozov, V. G. and Vybornov, O. Yu. Vysokomol. Soedin. (B) 1969, 11, 589

8 Ger. Pat. 847: 347 (1952) Ger. Pat. 932699 (1955); Ger. Pat. 1009809 (1957); Ger. Pat. 1108436 (1959); Japan Pat. 12510 (1965); Japan Pat. 10411 (1966)

9 Shostakovskii, M. V., Glaskova, N. P., Domnine, Ye. S., Belousova, L. V. and Shvortsova, G. C. Khim. Geterst. Soedin. $1971,9,958$

10 Cordes, E. H. and Dunlap, R. B. Acc. Chem. Res. 1969, 2, 329 and references cited therein

11 Strauss, U. P. and Gershfeld, N. L. J. Phys. Chem. 1954, 58, 747

12 Strauss, U. P., Gershfeld, N. L. and Crook, E. H. J. Phys. Chem. $1956,60,577$

13 Sinha, S. K. and Medalia, A. I. J. Am. Chem. Soc. 1957, 79, 281

14 Staab, H. A. and Mannschreck, A. Tetrahedron Lett. 1962, p 913; Mannschreck, A. and Staab, H. A. Ber. Dtsch. Chem. Ges. $1963,67,470$

15 Overberger, C. G., Salamone, J. C. and Yaroslavsky, S. J. Org. Chem. 1965, 30, 3580; Caesor, F. and Overberger, C. G. J. Org. Chem. 1958, 33, 2971

16 Olofson, R. A., Thompson, W. R. and Michelman, J. S. J. Am. Chem. Soc. 1965, 86, 1865

17 Haake, P., Bausher, L. P. and Miller, W. B. J. Am. Chem. Soc. $1969,91,1113$

18 Ringsdorf, H. and Walter, G. Makromol. Chem. 1971, 149, 295

19 Salamone, J. C., Ellis, E. J. and Israel, S. C. J. Polym. Sci. (B) $1972,10,605$ 